\title{
On the design and performance of a power electronics converter for the DeepWind project
}

Ritchie, Ewen; Leban, Krisztina; Trintis, Ionut; Nica, Florin Valentin Traian; Boian, Daniela; Biris, Ciprian; Burlacu, Paul Dan; Shivachev, Stoyan; Schmidt Paulsen, Uwe

\section{Published in:}

AIP Conference Proceedings

Link to article, DOI:

$10.1063 / 1.5117049$

Publication date:

2019

Document Version

Publisher's PDF, also known as Version of record

Link back to DTU Orbit

Citation (APA):

Ritchie, E., Leban, K., Trintis, I., Nica, F. V. T., Boian, D., Biris, C., Burlacu, P. D., Shivachev, S., \& Schmidt Paulsen, U. (2019). On the design and performance of a power electronics converter for the DeepWind project. In AIP Conference Proceedings: Technologies and materials for renewable energy, environment and sustainability: TMREES19 (1 ed., Vol. 2123). [030018] American Institute of Physics. AIP Conference Proceedings https://doi.org/10.1063/1.5117049

\section{General rights}

Copyright and moral rights for the publications made accessible in the public portal are retained by the authors and/or other copyright owners and it is a condition of accessing publications that users recognise and abide by the legal requirements associated with these rights.

- Users may download and print one copy of any publication from the public portal for the purpose of private study or research.

- You may not further distribute the material or use it for any profit-making activity or commercial gain

- You may freely distribute the URL identifying the publication in the public portal 


\section{On the design and performance of a power electronics converter for the DeepWind project}

Cite as: AIP Conference Proceedings 2123, 030018 (2019); https://doi.org/10.1063/1.5117049

Published Online: 17 July 2019

Ewen Ritchie, Krisztina Leban, Ionut Trintis, Florin Valentin Traian Nica, Daniela Boian, Ciprian Biris, Paul Dan Burlacu, Stoyan Shivachev, and Uwe Schmidt Paulsen

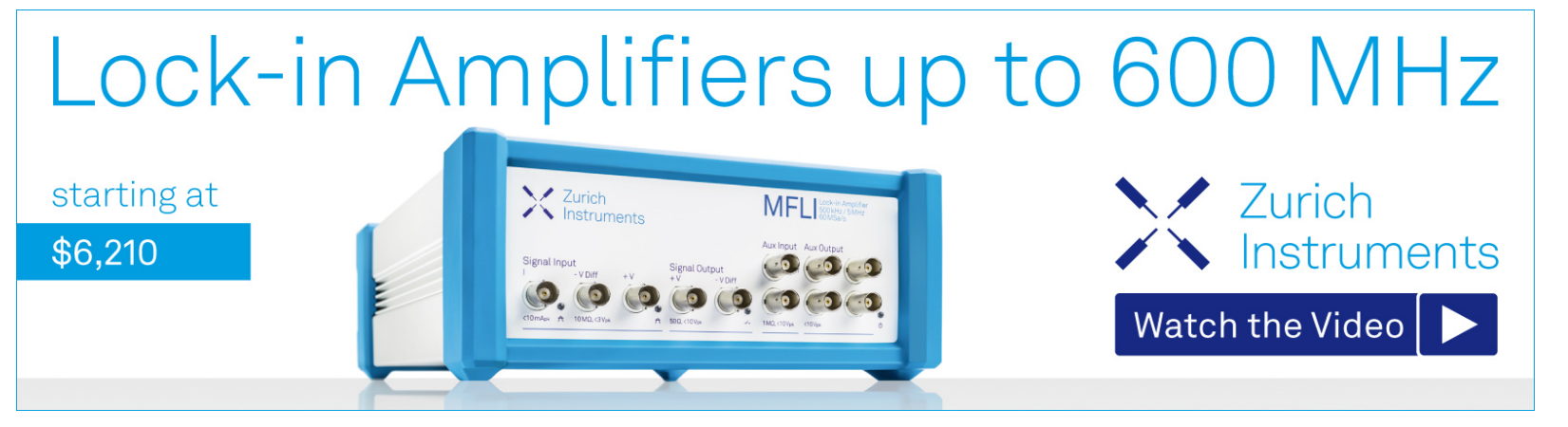




\title{
On the Design and Performance of a Power Electronics Converter for the DeepWind project
}

\author{
Ewen Ritchie ${ }^{1}$, Krisztina Leban ${ }^{1}$, Ionut Trintis ${ }^{1}$, Florin Valentin Traian Nica ${ }^{1}$, \\ Daniela Boian ${ }^{1}$, Ciprian Biris ${ }^{1}$, Paul Dan Burlacu${ }^{1}$, Stoyan Shivachev ${ }^{1}$, Uwe \\ Schmidt Paulsen ${ }^{2 a}$ \\ ${ }^{1}$ Department of Energy Technology, Aalborg University, Denmark \\ ${ }^{2}$ Department of Wind Energy, DTU, Risø Campus, Denmark \\ ${ }^{a}$ Corresponding author: uwpa@dtu.dk
}

\begin{abstract}
DeepWind is a vertical axis wind turbine (VAWT) concept, with the turbine rotor mounted on a floating spar buoy with the generator at the bottom up to $300 \mathrm{~m}$ below the sea. To control the starting, variable speed and overspeed limitation operation of the VAWT, the only method available is to control the torque and speed of the generator. A four quadrant, three level, neutral point clamped inverter configuration is proposed and the design of this discussed. Various operational features are tested on a small scale laboratory version. Sample test results are given. The challenges of the DeepWind marine application are presented and discussed and some solutions are proposed.
\end{abstract}

\section{INTRODUCTION}

DeepWind is a vertical axis wind turbine (VAWT) concept, with the turbine rotor mounted on a floating spar buoy with the generator at the bottom, Figure( Fig.) 1. The concept is described in [8] and the generator is described in [6]. To control the starting, variable speed and overspeed limitation operation of the VAWT, the only method available is to control the torque and speed of the direct drive, three phase AC permanent magnet generator. Control of the power flow is the only method available to control the Darrieus turbine, and power flow from the grid to the shaft is required for starting. In principle this is a well-established technology that was demonstrated early in the DeepWind project with a small scale prototype [13]. A properly designed power electronics converter will enable starting, stopping and generation, two kinds of emergency braking and grid code compliance. This may be effected by employing a drive system as shown in Fig. 2. The functions will require appropriate control systems, not covered in this paper. In the DeepWind project, a study of the power converter was carried out. Challenges are to design a high reliability four quadrant inverter suitable for a site where the generator is mounted at a sea depth of up to $300 \mathrm{~m}$. DeepWind employs a Darrieus wind turbine and ratings of $5 \mathrm{MW}$ and $20 \mathrm{MW}$ are planned, with a planned demonstrator rated $500 \mathrm{~kW}$. The projected shaft speeds for these are 5.4, 1 and $30 \mathrm{rpm}$ respectively. This makes the torque, hence the generator diameter, very large. To explore possibilities to reduce the diameter, a preliminary study of the effects of applying low full load frequencies of 6 and $15 \mathrm{~Hz}$ on the generator side has been made [12]. 


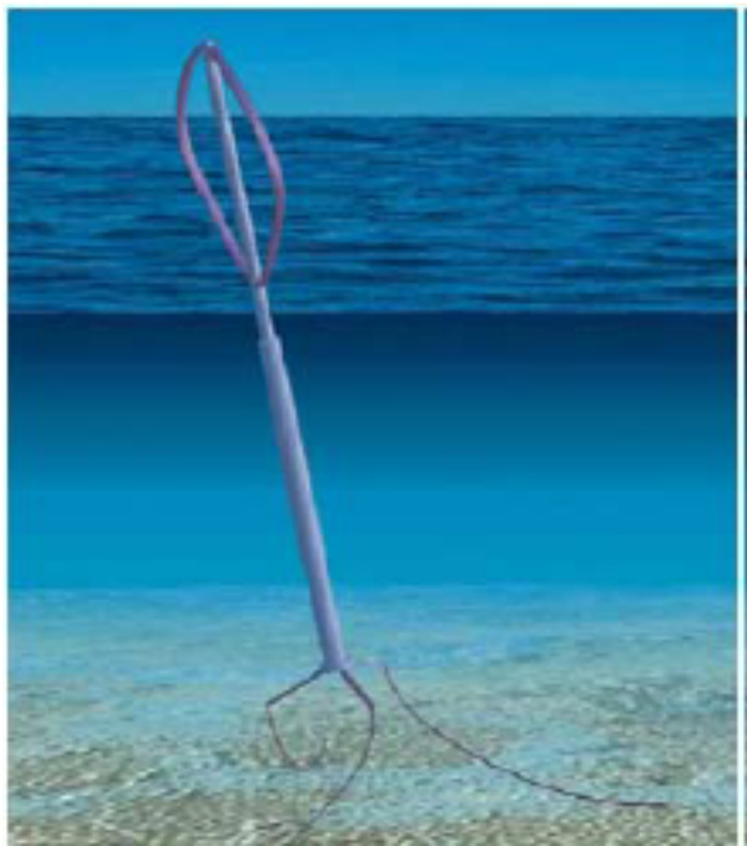

FIGURE 1. Preliminary Illustration of the DeepWind concept [14].

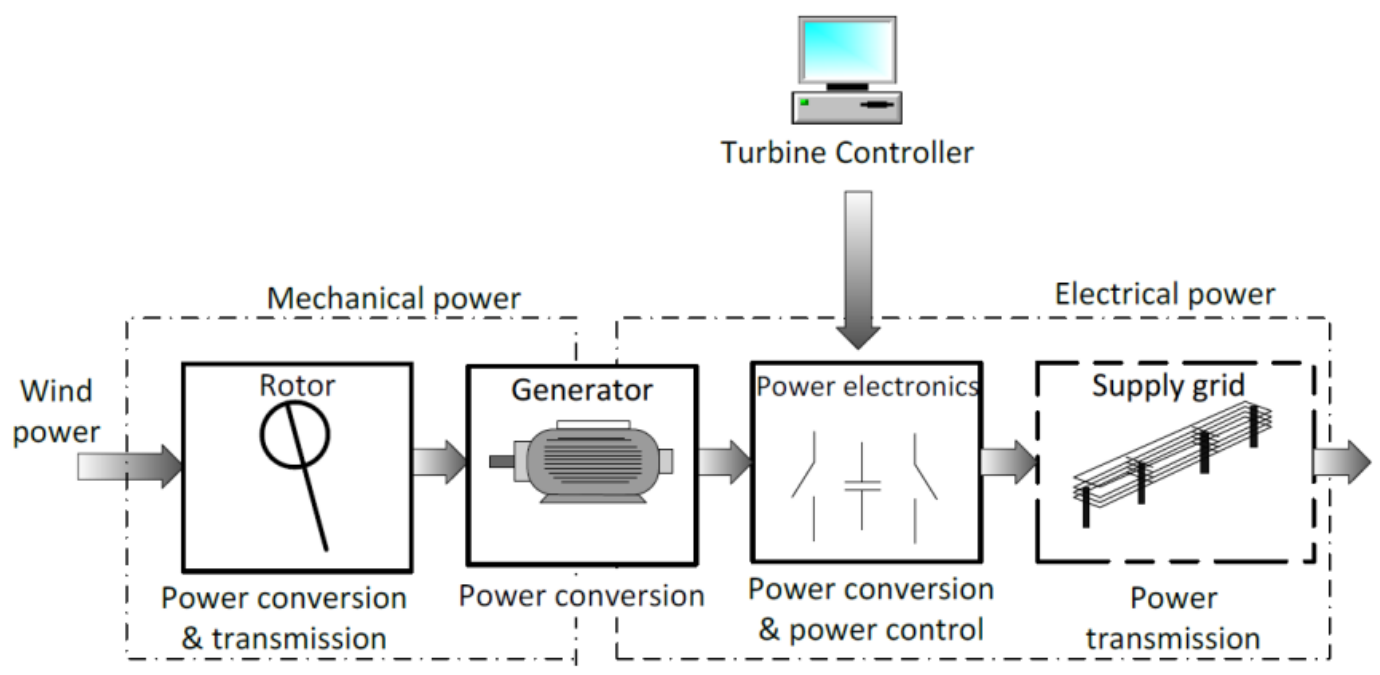

FIGURE 2. Diagram of the power flow in the DeepWind system during normal operation. The generator is acting as a generator in normal production, [12].

At these low frequencies, and the lower frequencies obtaining for wind speeds less than nominal speed, the large power transistors in the power converter expand and contract thermally, during every cycle of the power frequency, which puts added repeated stress on the internal components of the transistor, adversely affecting the reliability of the transistors [1]. It is planned to generate at a nominal voltage of $13.5 \mathrm{kWrms}$ on the $20 \mathrm{MW}$ version, to reduce the need for parallel connected output transistors. To reduce the blocking voltage on each output transistor to half the direct current (DC) value, a neutral point clamped, three-level architecture was selected, [2, 3], Fig. 3. As the inverters function by high speed modulation, filters are necessary both on the generator side and on the grid side. 
A mathematical model for the three-level, neutral point clamped (NPC) converter was implemented and verified by testing in the laboratory, both as a generator side converter and as a grid side converter, in a range of normal and abnormal conditions, [12]. Work has continued after the closure of the DeepWind project, and is reported elsewhere, e.g. [5].

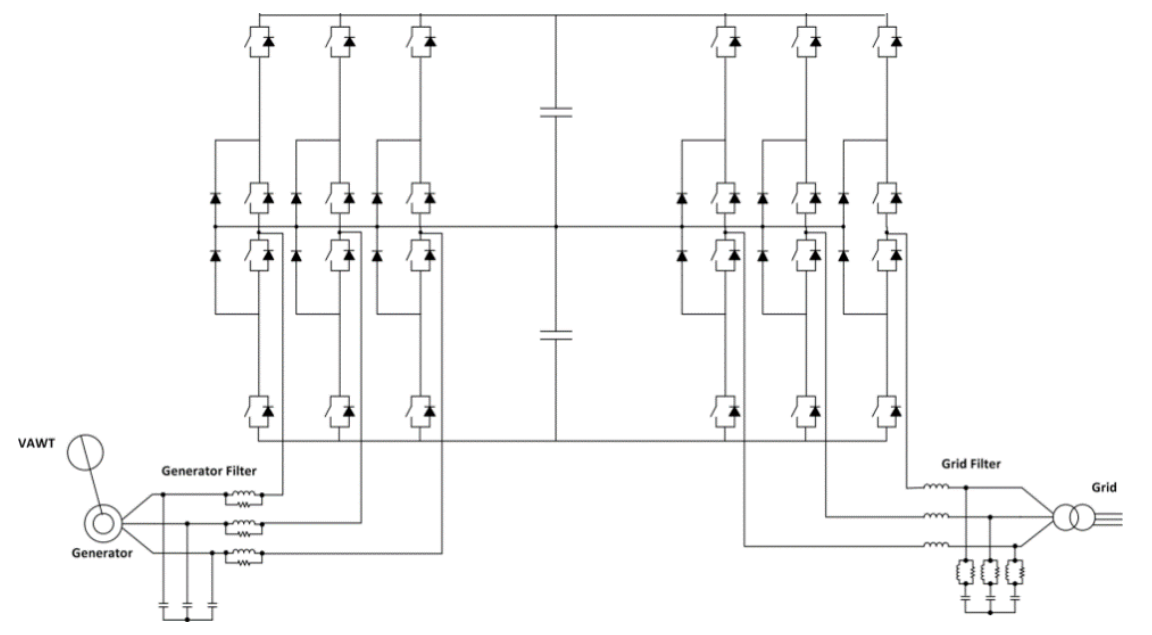

FIGURE 3. Diagram of a Four Quadrant, Three Level, Neutral Point Clamped inverter [2, 3].

\section{SPECIAL CHALLENGES ASSOCIATED WITH DEEPWIND VAWT SYSTEM}

As the generator power converter plays such an important part in the VAWT generating system, it must have a high reliability. This is especially important in view of the inaccessibility of the installation site. The converter should be installed in the near vicinity of the generator to ensure a short cable connection between the two and to facilitate control of the power flow. The electrical connection between the generator and power converter and that between the power converter and the point of connection to the grid must be very reliable despite the required continuous flexing caused by wave motion of the sea.

The installation could be fixed to the generator housing, in which case the challenge is to ensure that the connections inside the converter do not become inadvertently short-circuited by ingress of the high pressure (up to around 32 bar) sea water. In this case, there should be no relative movement between the converter and the generator. An alternative could be to install the converter, and other sensitive equipment, in a watertight enclosure, mounted on a floating spar buoy, as sketched in Fig. 4. The requirement for avoiding short-circuiting by sea-water remains, but the external pressure is much reduced, being close to atmospheric pressure. The influence of sea water on the housing is now restricted to splashing or wave action. In this case, the challenge is to provide a reliable flexible umbilical cable between the converter and the generator as the short cable will be subjected to constant movement between the VAWT structure and the floating enclosure. Any connection between a power electronics enclosure and the generator must also carry power to operate the controlled magnetic bearings and any cabling required for instrumentation.

Because of the deep water at the erection site, the distance to the point of connection to the power system grid is unavoidably very long, several kilometers. It is advantageous to transport power over this distance at medium voltage, around $20 \mathrm{kV}$ to avoid the losses associated with high current. The input to the converter from the generator is variable voltage and frequency, e.g. ranging from $0 \mathrm{~Hz}$ at startup and during some braking regimes, and from $3 \mathrm{~Hz} \mathrm{to} 6 \mathrm{~Hz}$ during normal generation; the voltage ranges similarly from $0 \mathrm{~V}$ to $13.5 \mathrm{kV}$, rms line voltage. 


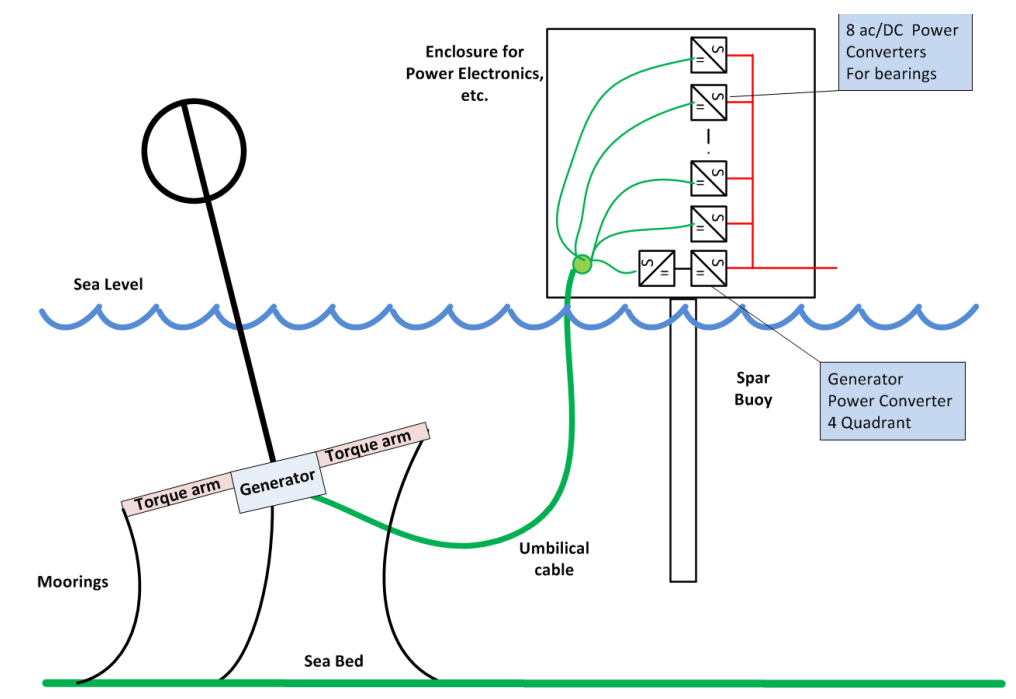

FIGURE 4. Diagrammatic sketch showing the generator power converter and the bearing converters installed in an enclosure mounted on a spar buoy, close to the VAWT.

\section{FUNCTION SPECIFICATION OF THE CONVERTER}

The main function of the generator power converter is to control the power flow from the entire VAWT system by controlling the generator shaft speed. The turbine control unit determines the required operating speed based on the actual measured wind speed, see Fig. 2. The voltage and frequency from the generator are both directly proportional to the shaft speed, and the generator frequency is very low at all times in an effort to reduce the required generator diameter [6]. The voltage and frequency of the grid are fixed. The function of the power converter then, is to match these to those of the generator, and enable the generator to supply power to the grid at all times during operation, in response to control signals from the turbine controller. The direction of power flow is from the VAWT to the grid.

As the Darrieus VAWT is not self-starting by the action of the wind, the power converter is required to take power from the grid and drive the generator as a motor until the VAWT is accelerated to sufficient speed so that it develops enough torque to drive the acceleration to operating speed, Fig. 5. In this case, the turbine controller requires the generator to start, but the start and acceleration process is controlled autonomously by the power electronics controller, monitoring the torque and until the speed is reached where control may be returned to the turbine control unit.

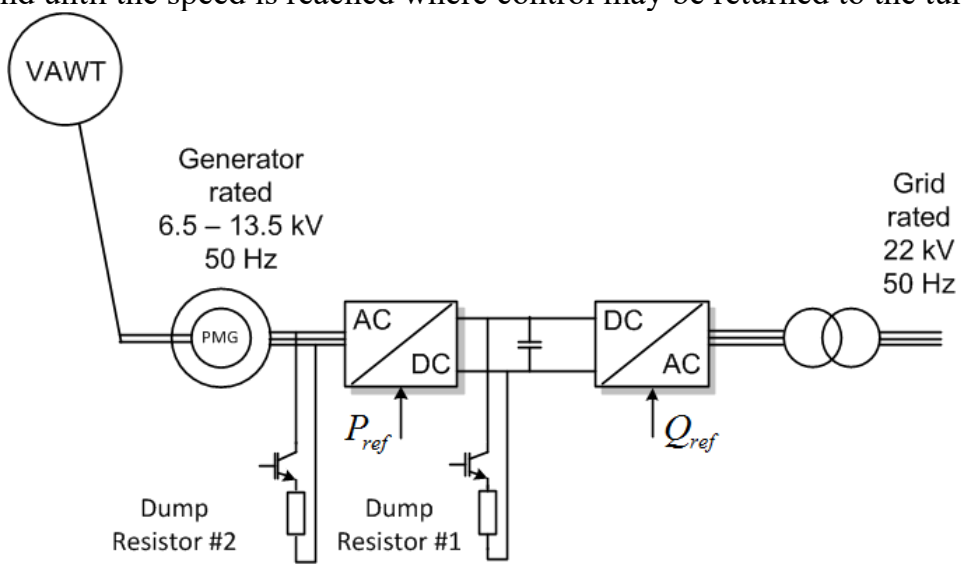

FIGURE 5. Diagram showing the drive line of the VAWT with direct drive permanent magnet generator, full power, four quadrant electronic converter, two dump resistors for emergency braking and grid transformer. 
When the VAWT is required to stop rotating for any reason during normal operation, control is returned to the power converter, which increases the load torque by increasing the generated power until the speed is reduced. This process then continues under autonomous control by the converter, until the shaft is at standstill. The shaft may then be held at standstill by autonomous control of the power converter if required.

The Dump resistors, Fig. 5, are not activated during any of the foregoing regimes of operation. If the connection to the grid is lost the generator can no longer load the VAWT normally, and any wind torque will cause the turbine to accelerate towards the limit of safe operation. This is an emergency situation and control is returned to the power converter which then diverts power from the DC link circuit to be dissipated in Dump Resistor \#1, see Fig. 5. This will apply braking torque to the shaft assembly and bring the VAWT safely to a standstill under control. Control is effected by modulation of the generator side inverter. This is possible because the generator is excited by permanent magnets that remain functional, enabling generation of voltage so long as the shaft rotates. This method of braking is able to hold the shaft at standstill.

If the generator side power converter ceases to function the generator can no longer load the VAWT normally and again the turbine may accelerate out of control. In this case, Dump Resistor \#1 cannot be used for braking, and Dump Resistor \#2 must be connected directly at the generator terminals as back-up emergency braking, see Fig. 5 . The torque applied by current flowing in this resistor is not immediately controllable, but braking torque will be applied so long as the shaft rotates. This method of braking is not able to hold the shaft at standstill.

If all connection from the generator to the power converter and Dump Resistors is lost, another alternative emergency braking system must be applied [9].

A challenging feature of the power converter is that the power frequency on the generator side is very low, currently $6 \mathrm{~Hz}$ max., for the $5 \mathrm{MW}$ version. This may be reduced as a result of further design studies, and will be even less for the for the $20 \mathrm{MW}$ version. The thermal time constant of the output devices in the inverters is such that the internal components of the transistors expand and contract in the course of a single cycle of the generator power frequency. This causes repetitive thermal stresses on the internal joints of the transistors and may lead to early failure. Research is in hand, to determine how best to meet this challenge [11].

\section{PROPOSED CONSTRUCTION OF THE POWER ELECTRONICS SYSTEM}

For convenience and availability, the power converter for the small scale $1 \mathrm{~kW}$ demonstrator was a commercial, two level, pulse width modulated, four quadrant converter, installed remotely in a dry location, on-shore [13]. It was connected to the $400 \mathrm{~V}, 50 \mathrm{~Hz}, 3$ phase mains supply, [13]. In principle this is the same as the system proposed for the full scale versions. However the power to be handled in the full scale versions would cause the current to be excessive, if the usual $690 \mathrm{~V}$ industrial voltage were to be selected for operation; the required current would be around 4200 [A] for the $5 \mathrm{MW}$ version. This would require a large number of parallel connected output devices. If one of the paralleled output devices were to fail the converter may continue to function, but the remaining devices would be more heavily loaded, making it necessary to operate at reduced power, or risk a domino effect causing complete failure. In addition the necessary large number of devices and connections may be expected to reduce the system reliability.

Semiconductor output devices are currently in a rapid development phase, and engineering samples of $15 \mathrm{kV}$ silicon carbide field effect transistors $(\mathrm{SiC})$ are currently being tested prior to commercial release, which is anticipated in the near future. As a three-level converter was selected, these $\mathrm{SiC}$ devices would be suitable for a working line voltage of around $20 \mathrm{kWrms}$, see Fig. 3 [2,3]. This corresponds to a DC link voltage around $16 \mathrm{kV}$, meaning a required blocking voltage in the three-level configuration of some $8 \mathrm{kV}$, leaving a comfortable safety margin to the transistor rating. This suits the DeepWind application very well, as the required full load current of the $5 \mathrm{MW}$ version would fall correspondingly to around 150 Arms which does not require parallel connection of output devices, thus improving the reliability of the system. As the output devices will need to be liquid cooled, the reduction in the number of devices simplifies the cooling circuit, too.

The proposed architecture of the power converter is a four quadrant, three level, neutral point clamped inverter as shown in Fig. 3, but with the addition of Dump Resistors for emergency braking as shown in Fig. 5. The three level inverter exhibits several advantages that are attractive for the DeepWind application, notably reduced voltage exposure for the output transistors, relatively low harmonic content of the output waveforms, which reduces the required size of the filters on the output, the ability to control common mode voltage, which reduces the leakage current, and reduced switching and conduction losses in the output transistors [10]. A disadvantage is that the complexity of the control system is increased. 
A simplified conceptual explanation of the operation of the three level inverter is based on Fig. 6. This shows a three level inverter operated by three, three position switches, each switch can either connect $\mathrm{VDC}^{+}, 0$, or $\mathrm{V}_{\mathrm{DC}}{ }^{-}$to its output terminal. By selecting these appropriately, a three-phase system of voltages may be constructed at the ABC terminals. The combination of the time-changing switching of the inverter circuit and the spatial displacement of the various coils in the electrical motor/ generator, illustrated in Fig. 7 leads to the concept of space vectors, illustrated in Fig. 8a, where each possible on/off combination of switching of the transistors of the inverter leads to a vector of magnetic field in the electrical machine, by applying current to the coils of the machine. By selecting the possible vectors, one by one, in an appropriate sequence, a virtual rotating sine wave of magnetic flux may be constructed in the generator, and similarly for the grid side. This is reflected in the voltage and current waveforms. Many different strategies may be devised for determining the sequence and will be the subject of R \& D studies during the final design process, in order to determine the best modulation sequence for the DeepWind application.

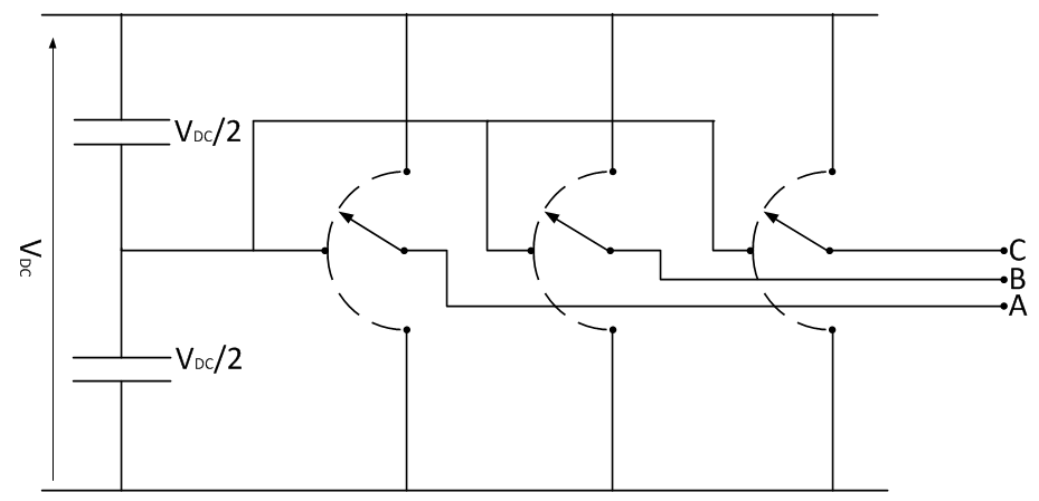

FIGURE 6. Concept diagram used to explain the working of a three level inverter [3].

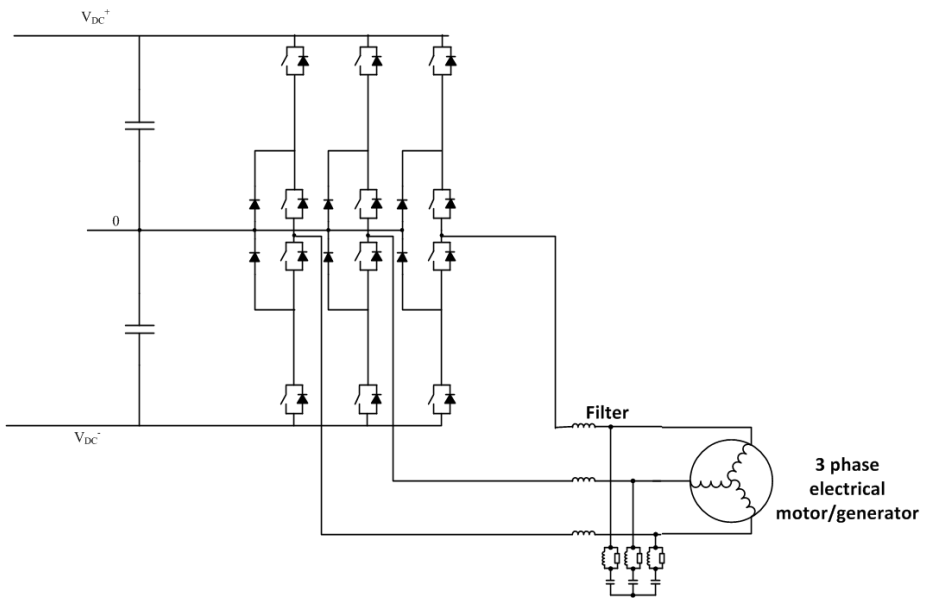

FIGURE 7. Concept diagram used to explain the working of a three level inverter [3]. 


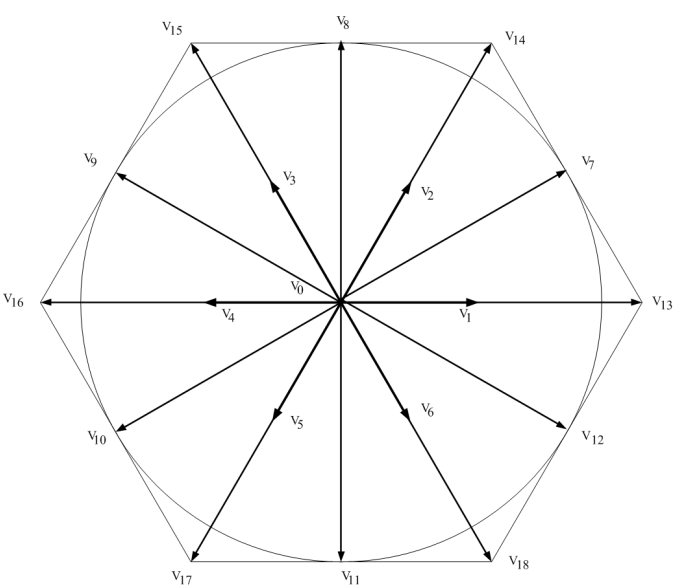

(a)

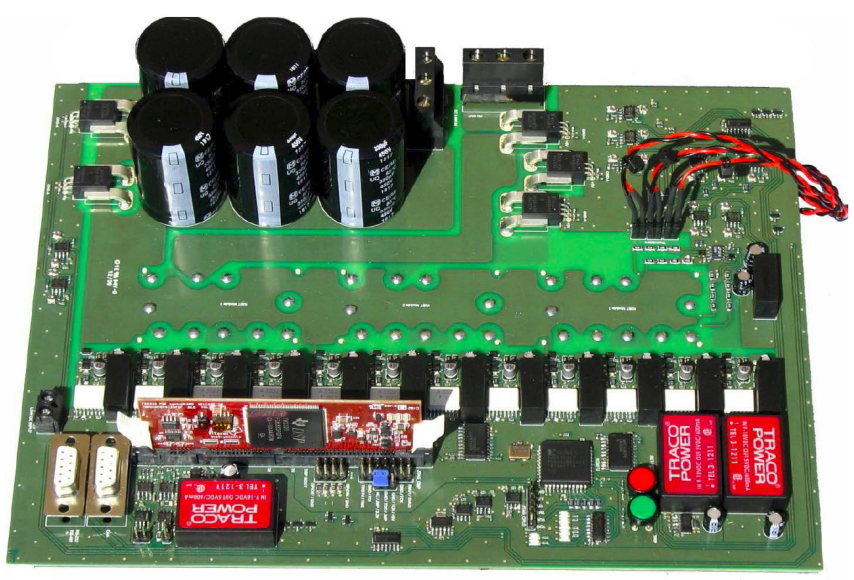

(b)

FIGURE 8. a) Illustrating the 18 possible space vectors of magnetic field that may be obtained by selecting the 18 possible combinations of switches in Fig. 7 [3]. b) Photo of one of the $5 \mathrm{~kW}$ scale model prototype NPC converters made for DeepWind project laboratory tests [3].

\section{SITING OF THE CONVERTER}

Siting of the power electronics system for DeepWind poses special challenges and needs closer study in order to finalize the physical design. The challenges are associated with the depth of sea-water, up to around $300 \mathrm{~m}$ and the siting of the generator at the bottom of the floater, which may be at around $250 \mathrm{~m}$ depth.

A subsea location of the power electronics presents special challenges and to allow the use of standard electronics components an initial proposal was that the housing should be air filled and pressure compensated, [13]. This will require air conditioning to maintain a dry atmosphere inside the housing and avoid condensation on the active parts. A liquid cooling system with heat transfer to seawater at around $4{ }^{\circ} \mathrm{C}$ will require pre-heated liquid, to prevent condensation. The housing will require comprehensive corrosion protection including surface treatment and cathodic protection. Careful attention must also be given to the selection and dimensioning of insulating materials. An external power cable to the point of common connection to the grid will be necessary and will be subject to constant movement.

If the option of installation of the electronics converters in a floating sub-station, mounted on a spar buoy is selected, see Fig. 4, the immediate environment of the converters will be much more easily protected and kept dry. However, there will be a flexible medium voltage umbilical cable from the floating sub-station to the generator, carrying the external power and instrumentation circuits. This cable will be subject to constant movement and will contain cores carrying essential services such as power from the generator, eight circuits with power to the controlled magnetic bearings, and instrumentation circuits. The external power cable to the point of common connection to the grid will also be necessary and will be subject to constant movement. Existing marine, sub-sea and deep-sea technologies for industrial solutions can be adapted to answer some of these specific challenges.

\section{SMALL SCALE LABORATORY PROTOTYPE AND TESTING}

For the DeepWind concept two small scale $5 \mathrm{~kW}$ prototype NPC inverters were designed, built and tested in the laboratory for performance, see Fig. 8b. The machine side inverter was tested [7,5], in association with the small scale prototype generator of [6] and the grid side converter was tested driving the $400 \mathrm{~V}, 3$ ph., $50 \mathrm{~Hz}$ mains [2,3]. The neutral point clamping ensured equal sharing of the voltage stress among the components $[2,3]$. The machine side inverter was able to control the generator when operating in all functions described above, without the use of a shaft position or motion sensor. Important features of the grid side inverter are common mode voltage (CMV) and total harmonic distortion (THD). Both of these are affected by the modulation strategy adopted. Samples of test results are shown in Fig. 9a-c These show that the current and voltage output of the inverters is close to a sine wave, which is desirable and that the generator may be operated as a motor during acceleration.

Many modulation strategies have been proposed in [2,3] and studied for DeepWind [12]. The results obtained from four modulation strategies are summarized in Table 1. The strategies reported here are Nearest Three Vectors (NTV), 
Zero Common Mode (ZCM), One Large One Medium (OLOM) and Zero Small Medium Large (ZSML). The nomenclature here refers to space vectors commonly used in electrical machine and power systems analysis.

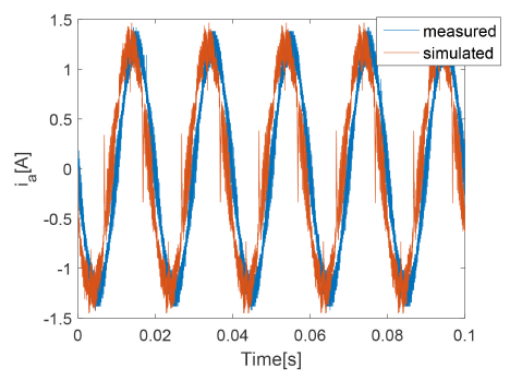

(a)

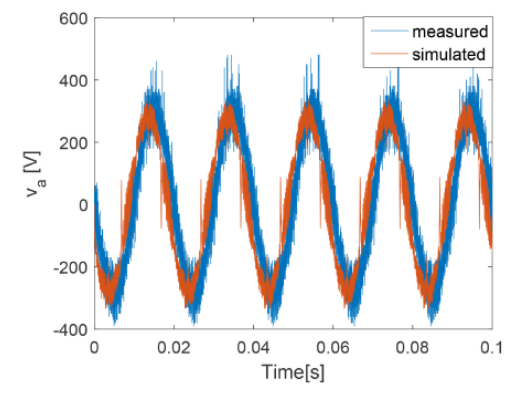

(b)

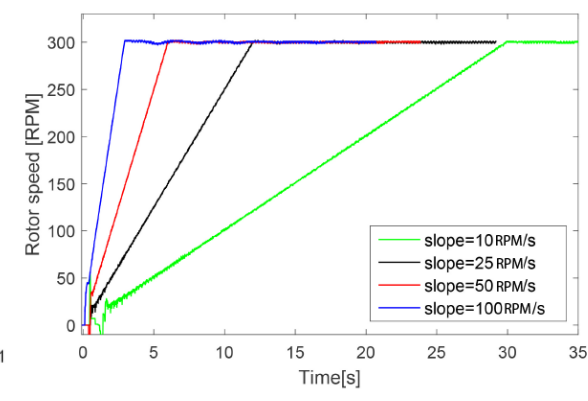

(c)

FIGURE 9. a) Measured and simulated phase current in a three level NPC inverter, [5]. b) Phase voltage measured at the load, [5]. c) Measured rotor speed at start-up for various ramp slopes. Final speed, $300 \mathrm{rpm}$ and no-load, [5].

\section{SUMMARY AND CONCLUSION}

The three-level NPC inverter has been proposed for the DeepWind application. Four quadrant operation is obtained by connecting two of these back to back, one on the generator side and one on the grid side, allowing full control of power flow in generating mode or motoring mode. The total harmonic distortion and the common mode voltage can both be limited to acceptable levels by applying an appropriate modulation strategy. The three-level, NPC topology reduces the voltage exposure of the individual output transistors, allowing medium voltage operation, with a large safety margin, which combined with the ability to apply a single transistor for each switch, to supply the current demand improves the reliability of the inverters. The four quadrant operation was demonstrated on the $1 \mathrm{~kW}$ DeepWind demonstrator, and the three-level NPC inverter configuration has been successfully tested in the laboratory on a small scale as a motor/generator side converter, and as a grid side inverter. Further work is necessary to determine the exact method for switching the new SiC FET transistors and to determine which existing sub-sea application methods are the best to use. This configuration, combined with the two Dump Resistors offers all the functions described.

Continued work is needed to establish the best mechanical configuration of the electrical installation and siting for the DeepWind, marine application, to determine the optimum siting for the electric power converter. It is especially important to avoid expensive maintenance operations and replacements at the bottom of the floater, making all knowledge that helps to increase reliability very important. Further work is needed to develop the correct cable for use in the DeepWind application. At the end of the day, the exact configuration of the power converter will be that which costs least, both in terms of manufacture and maintenance costs.

TABLE 1. Illustrating the effects of various modulation strategies on the grid side inverter.

\begin{tabular}{lllll}
\hline & NTV & ZCN & OLOM & ZMSL \\
\hline Phase/Line voltage levels & $9 / 5$ & $3 / 5$ & $7 / 5$ & $9 / 5$ \\
\hline Modulation index & 1 & 0.866 & 1 & 1 \\
DC link balancing & Natural balancing & Natural balancing & Natural balancing & Natural balancing and Forced balancing \\
CMV levels V & $\pm 200, \pm 100$ & \pm 100 & \pm 100 & \pm 100 \\
Simulated ph-ph THD & $27.93 \%$ & $51.51 \%$ & $34.27 \%$ & $26.55 \%$ \\
Measured ph-ph THDv & $29.88 \%$ & $55.03 \%$ & $36.53 \%$ & $28.45 \%$ \\
\hline
\end{tabular}

\section{ACKNOWLEDGMENTS}

This work, part of the result of Work Package 5 of the INFLOW project was supported by the European Union's Seventh Programme for research, technological development and demonstration under grant agreement No 296043 and the DeepWind project for funding under grant agreement No. 256769. Asger B. Abrahamsen ${ }^{2}$ is acknowledged for support on editing the manuscript. 


\section{REFERENCES}

1. F. Blaabjerg, S. Munk-Nielsen, K. Pedersen and V. Popok, "Center Of Reliable Power Electronics (CORPE)"; Centre of Excellence at Aalborg University.

2. D. Boian, C. Biris, R. Teodorescu and M. Sztykiel, "Development of Modulation Strategies for NPC Converter Addressing DC Link Voltage Balancing and CMV Reduction“, IEEE PEDG conference Aalborg, Denmark, June 2012.

3. D. Boian and C. Biris; "Development of Modulation Strategies for NPC Inverter Addressing DC Link Balancing and CMV Reduction" MSc Dissertation, Aalborg University, May 2012.

4. DeepWind, 2015, http://www.deepwind.eu/ - reports, photos and videos.

5. O. D. Kristensen, C. Ionita, M. T. Thomé and M. Porebski, "Start-up of Permanent Magnet Synchronous Machine Using Three-level Inverter"; Aalborg University, Semester project, Dec. 2015.

6. K. Leban, E. Ritchie and U. S. Paulsen, "Specification, Design and Performance of the Generator for the DeepWind project “, EUROMECH Colloquium on Scientific and Technological Challenges in Offshore Vertical Axis Wind Turbines, Delft, 2016, (submitted)

7. F.V.T. Nica, "Sensor less Control of PMSM Using Three Level NPC Converter", MSc Dissertation, Aalborg University, May 2014.

8. U S. Paulsen, H. A. Madsen, I. Baran, J. Hattel, E. Ritchie, K. Leban, H. Svendsen and P. A. Berthelsen, "DeepWind-from idea to 5 MW concept " Energy Procedia Volume 53, 2014, Pages 23-33

9. U. S. Paulsen, M. Borg, H. A. Madsen, T. Friis-Pedersen, J. Hattel, E. Ritchie, C. S. Ferreira, H. Svendsen, P. A. Berthelsen and C. Smadja, "Outcomes of the DeepWind conceptual design" Energy Procedia Volume 80, 2015, Pages 329-341, doi:10.1016/j.egypro.2015.11.437

10. R. Ramin, M. Di Lella and V. Demuth, "The Low and Medium Power Module for High Integrated Applications" Semikron, Application Note 2008.

11. P. D. Reigosa, F. Iannuzzo, S. Munk-Nielsen and F. Blaabjerg, "New layout concepts in MW-scale IGBT modules for higher robustness during normal and abnormal operations." Proceedings of the 31st Annual IEEE Applied Power Electronics Conference and Exposition (APEC). Long Beach: IEEE Press, 2016. p. 288 - 294.

12. E. Ritchie, "Design tools for submersible converter", D3.32, Tech. Report, EU FP7 project, Future Deep Sea Wind Turbine Technologies, 2014.

13. I. Trintis, "Report - Power Electronics for WP3 DeepWind Project - September 2012" DeepWind project working report, 2012.

14. L. Vita, U. S. Paulsen and T. Friis Pedersen, "A novel floating offshore wind turbine concept: new developments." DeepWind project report, 2010. 